\title{
Building Resilience in Lagoon Social-Ecological Systems: A Local-level Perspective
}

\author{
Fikret Berkes, ${ }^{\star}$ and Cristiana S. Seixas \\ Natural Resources Institute, University of Manitoba, Winnipeg, Manitoba R3T 2N2, Canada
}

\begin{abstract}
Building resilience in integrated human and nature systems or social-ecological systems (SES) is key for sustainability. Therefore, developing ways of assessing resilience is of practical as well as theoretical significance. We approached the issue by focusing on the local level and using five lagoon systems from various parts of the world for illustration. We used a framework based on four categories of factors for building resilience: (1) learning to live with change and uncertainty; (2) nurturing diversity for reorganization and renewal; (3) combining different kinds of knowledge; and (4) creating opportunity for self-organization. Under each category, the cases generated a number of items for
\end{abstract}

\section{INTRODUCTION}

Resilience theory offers a vision of sustainability, not as stability, but as persistence borne out of change-more specifically, out of adaptive renewal cycles in the sense of Gunderson and Holling (2002). Resilience is related to the magnitude of shock that a system can absorb and still remain within a given state, the self-organization capability of that system, and its capacity for learning and experimentation. Managing for resilience implies maintaining options in a world of rapid change in which surprise is likely and the future unpredictable; hence, resilience is forward-looking (Folke and others 2002). Operationalizing resilience and making a transition from theory to practice require estimators or measures of resilience. According to

Received 28 September 2003; accepted 21 July 2004; published online 28 November 2005.

*Corresponding author; e-mail: berkes@cc.umanitoba.ca building resilience, and potential surrogates of resilience, that is, variables through which the persistence of SES emerging through change can be assessed. The following factors were robust across all five lagoon SES cases: learning from crisis, responding to change, nurturing ecological memory, monitoring the environment, and building capacity for self-organization and conflict management.

Key words: resilience; adaptive renewal cycles; lagoons; monitoring; knowledge; diversity; selforganization; social-ecological systems; institutions; governance; Brazil.
Carpenter and others (2005), “a resilience surrogate is a proxy used to assess resilience in a socialecological system". Surrogates are different from indicators because they are forward-looking, rather than measures of the current or past state. This paper is an exploration to develop conceptual points regarding surrogates of resilience, using lagoon systems as examples.

Lagoon or estuarine systems provide suitable settings for developing measures of resilience for three reasons. First, lagoon systems tend to be human-dominated and are used intensively. They are geographically bounded and readily identifiable as integrated systems of human and nature. They are social-ecological systems (SES) (Berkes and Folke 1998; Walker and others 2002) in which human activity is often an integral part of lagoon ecology. Second, many processes in lagoon SES, such as hydrology and resource use, follow annual cycles. Third, lagoons are often subject to shocks 
and directional change, as in depletion-and-recovery cycles, making a good fit with resilience thinking. Hence, lagoon SES tend to make good laboratories for the study of resilience, discrete human-dominated ecosystems with cycles and directional change (Seixas and Berkes 2003).

The objective of the paper is (1) to identify the characteristics of linked SES that build resilience, and (2) to search for surrogates of resilience that are robust across lagoon SES. We use a local-level, community-based perspective because our objective is to understand resilience at the local level. First we describe a lagoon case study from Brazil (Ibiraquera) in which we have previously identified various factors that strengthen or weaken resilience. Second, we bring in selected additional lagoon cases from Brazil (Patos), India (Cochin), Sri Lanka (Negombo) and Turkey (Haylazli) to provide a comparative study.

The method for case selection follows the criterion of information available for identifying factors for resilience building from a local-level perspective. These five are either lagoons in which we have first-hand knowledge (Seixas and Berkes 2003; Lobe and Berkes 2004; Berkes 1986, 1992), or lagoons that are known to us and information is verifiable (Kalikoski and others 2002 for Patos; Amarasinghe and others 1997 for Negombo). Hence, our findings are generally valid for lagoons in semi-tropical developing countries in areas without heavy industrial concentration. Following the detailed study of one lagoon (Ibiraquera), we explore various factors that help build resilience and speculate on resilience surrogates.

\section{Case Study: Ibiraquera Lagoon, SOUTHERN BRAZIL}

Seixas and Berkes (2003) studied the management of the Ibiraquera Lagoon, Santa Catarina State, southern Brazil, using a historical case-study approach and a mix of qualitative and quantitative study methods. Ibiraquera is a brackish water lagoon, intermittently connected to the Atlantic Ocean by a channel that is usually opened by human actions and closed by natural processes (Figure 1). Fishers manage the lagoon opening to time the entry of young fish and shrimp from the ocean into the basin. Ibiraquera has four sub-basins, interconnected by channels, with a total area of about 900 ha. Pink shrimp (Farfantepenaeus paulensis and F. brasiliensis) and mullet (Mugil platanus, Mugil spp.) are the main resources. In 2000, there were about 350 licensed fishers with access to the resources of the Lagoon, plus many unlicensed fishers, living in seven communities in the area. Fishers from other communities outside the area also frequently fished in the Lagoon.

Tourism-related activities were the main source of income for most of the residents of the study area. Historically, small-scale fishing and agriculture were the major sources of income up until the 1970s, but they became less important to the local economy by the late 1990s. Fishing evolved from a subsistence-level activity in the 1950s to a marketoriented activity in the 1970s. In the 1990s, it became both a commercial and sport activity. The Ibiraquera area is popular for summer tourists. Although tourism started to develop in Ibiraquera by the late 1970s, the biggest tourism boom in the region occurred during the 1990s. For example, in the Barra da Ibiraquera, one of the seven communities in the area, the number of buildings increased about tenfold between 1990 and 2000 due to the construction of summer cottages and guesthouses.

Until the 1960s, the Lagoon fishery was managed communally, with flexible management practices based on local ecological knowledge and enforced by social rules. During the 1970s, local rules broke down and the Lagoon became open-access, due to several socio-economic changes, including the development of external markets for shrimp and technological innovations in fishing gears. Following a cycle of resource depletion, some local rules were restored and enforced by the government, and the system regained its productivity during the 1980s and early 1990s. After 1994, however, government enforcement weakened and conflict and competition between a number of user-groups built up again, leading to another cycle of management problems.

\section{Factors Affecting Resilience in Ibiraquera Lagoon}

Seixas and Berkes (2003) identified a number of key factors that affected resilience. Some resulted in the loss of resilience and others helped to build resilience. The four clusters of factors that weaken resilience, or indicate a reduction in resilience, included (1) the breakdown of local institutions (defined as rules-in-use) and the traditional authority system that governed fisher behavior; (2) rapid technological change leading to over-efficient and destructive resource use; (3) rapid socio-economic change through regional, national and international economic integration, especially for shrimp markets; and (4) institutional instability across the political scale, such as changes in the 


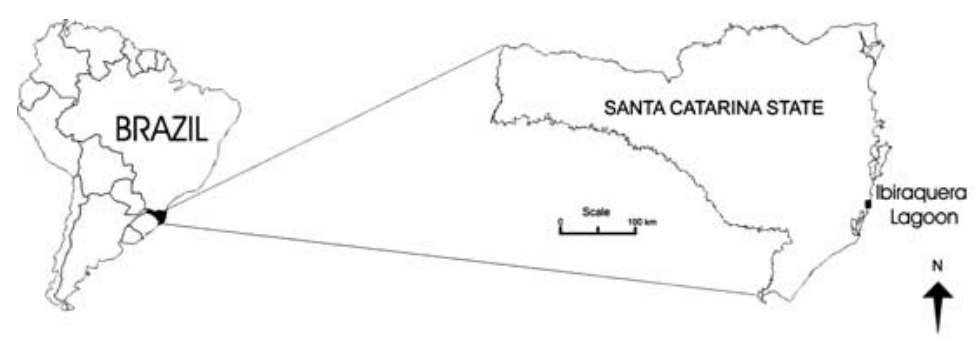

Figure 1. Map of the Ibiraquera Lagoon, Santa Catarina State, Brazil.

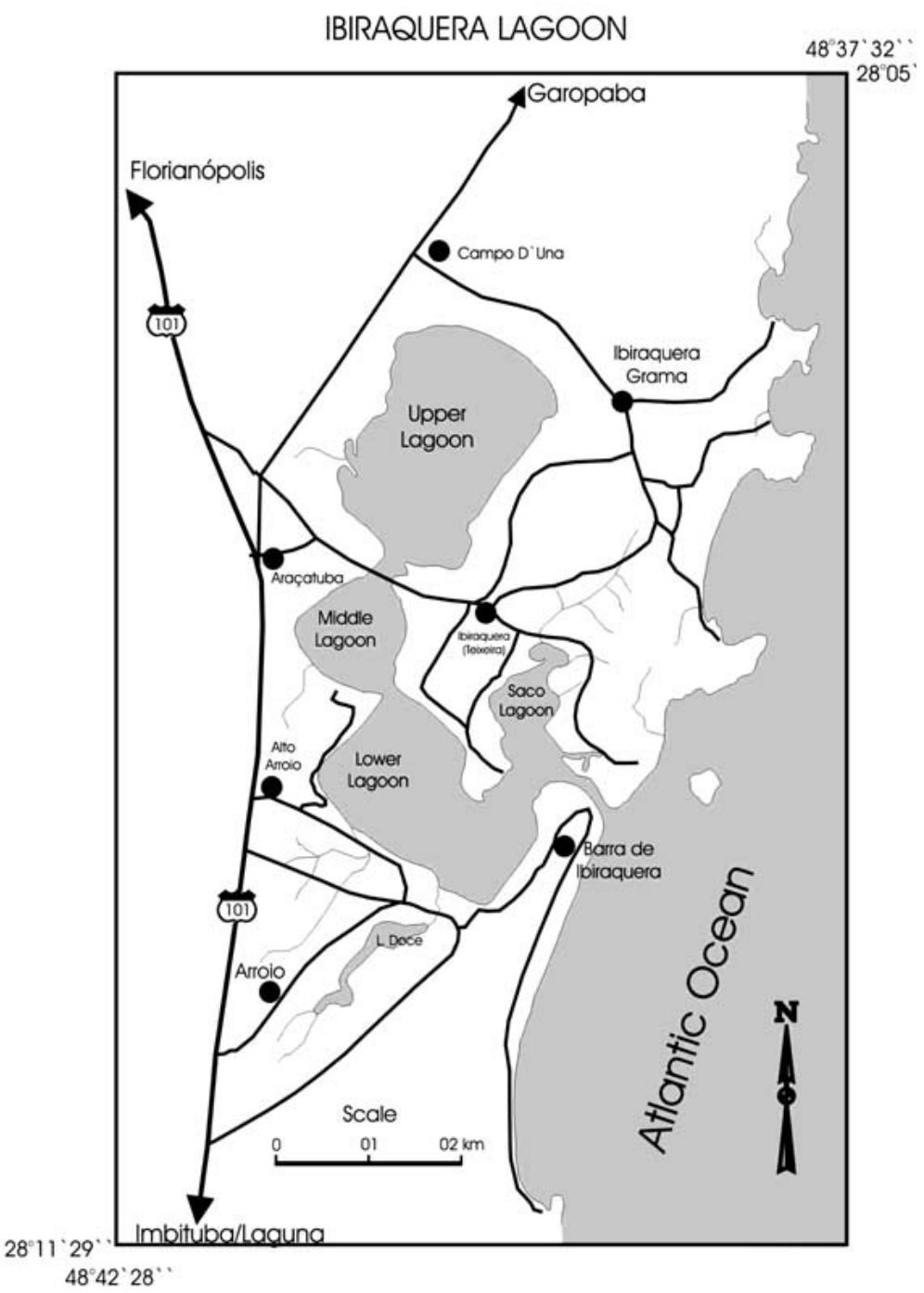

state and federal management institutions and the inability of the government to enforce fishing regulations.

On the other side of the ledger, Seixas and Berkes (2003) identified five clusters of factors that help build resilience: strong institutions; cross-scale interactions and communication; political space for experimentation; equity; and use of fishers' ecological knowledge as memory and a source of novelty. Institutions as a cluster of factors include the elements of robustness of rules-in-use, enforcement, and leadership. Four levels of organization were identified: institutions of local resource users, the regional umbrella organization of fishers (Colônia de Pescadores), State agencies, and the Federal Fishery Agency. Local institutions were key, as were strong government enforcement of rules in the recovery period of 1981-1994.

Cross-scale interactions refer to vertical interplay across different levels (Young 2002). Such interactions are important in determining the status of the resource and for the communication and 
sharing of knowledge. For example, the three regulations established during the 1981-1994 period (banning of all but cast-nets; banning of fishing with bright lights, increasing shrimp cast-net mesh size) involved cross-scale cooperation and information exchange. Cross-scale communication was important for the co-management of the lagoon using both scientific and local ecological knowledge. For example, local knowledge on the effect of large nets and fishing with bright lights was taken into account by the Federal Fishery Agency. Local fishers used scientific data to demand a change for larger mesh sizes for shrimp.

The Federal Fishery Agency included local fishers' input in the formulation of regulations, thus creating political space for experimentation. The case shows a multitude of changes, problems, and management responses, including a rich set of fishers' own management measures and fishers' rules incorporated into government management. Given the reality of top-down government management that historically characterized resource management in Brazil, the creation of such political space for experimentation was unusual by the standards of the early 1980s.

Resource access equity (equal opportunity) was the driving force in many of the changes and conflicts. The creation of equitable access improved management; loss of equity led to conflict and system breakdown. For example, the banning of overly efficient nets and butane gas lamps contributed to more equitable allocation of resources. Equity could not have been achieved if everyone used larger nets; the experience in the late 1960s and the late 1970s had already shown that it leads to resource depletion.

The use of fishers' memory and ecological knowledge as sources of innovation and novelty appears in two circumstances: in devising new regulations based on past arrangements, and in resource monitoring and management. For example, the banning of large nets in 1981 was inspired by the first attempts in 1971 to prohibit their use in two lagoon basins. The regulation prohibiting fishing in all of the channel areas was probably based on pre-1970s management practices.

\section{Building Resilience: Lessons from Five Cases}

To analyze the Ibiraquera Lagoon case, with crossreference to four other lagoon systems, we use a framework based on four categories of factors for building resilience: (1) Learning to live with change and uncertainty; (2) nurturing diversity for reor- ganization and renewal; (3) combining different kinds of knowledge; and (4) creating opportunity for self-organization. This framework emerges from the conclusions of a multi-year team study on the dynamics of social-ecological systems (Folke and others 2003). The results of the analysis are summarized in Table 1.

\section{Learning to Live with Change and Uncertainty}

Folke and colleagues (2003), among others, challenged the notions of managing for stability and constant resource outputs (for example, maximum sustainable yields) and hypothesized that building resilience requires accepting the inevitability of change and adapting to live with uncertainty and surprise. This cluster of factors deals with this issue, including disturbance and learning. Lagoon ecosystems are typically disturbance-driven, for example, through the opening and closing of the lagoon mouth and the migration of species in and out of a lagoon and estuary. All five cases in Table 1 show various examples of these factors. The first three (managing disturbance; learning from crises; building rapid feedback capacity to respond to environmental change) are almost universal.

Livelihood portfolios (mix of activities) are known to be important in coastal areas in many parts of the world (Allison and Ellis 2001), and are found in four of the five lagoon cases as well. These portfolios may involve a mix of fishing with other activities (for example, watermelon farming in Haylazli) and/or a mix of different kinds of fishing. For example, in the Negombo Lagoon, almost all fishers using the brush park technique also used other fishing methods, such as cast netting and gillnetting, as part of a portfolio of activities, "thus seasonal variations in fish yields [by technique are averaged out and] have little effect on overall income" (Amarasinghe and others 2002). In the stake net fishery, fishers take uncertainty into account by developing coping strategies on the basis of the information collected from their fellow fishers on variability in shrimp catches in space and time, and make bids for fishing sites on that basis (Amarasinghe and others 1997; u.s. Amarasinghe; personal communication).

\section{Nurturing Diversity for Reorganization and Renewal}

The second set of factors emphasizes the importance of diversity for resilience, not only as insurance for uncertainty and surprise (Perrings and 
Table 1. Clusters of Factors for Building Resilience from the Local Perspective in Lagoon Social-Ecological Systems

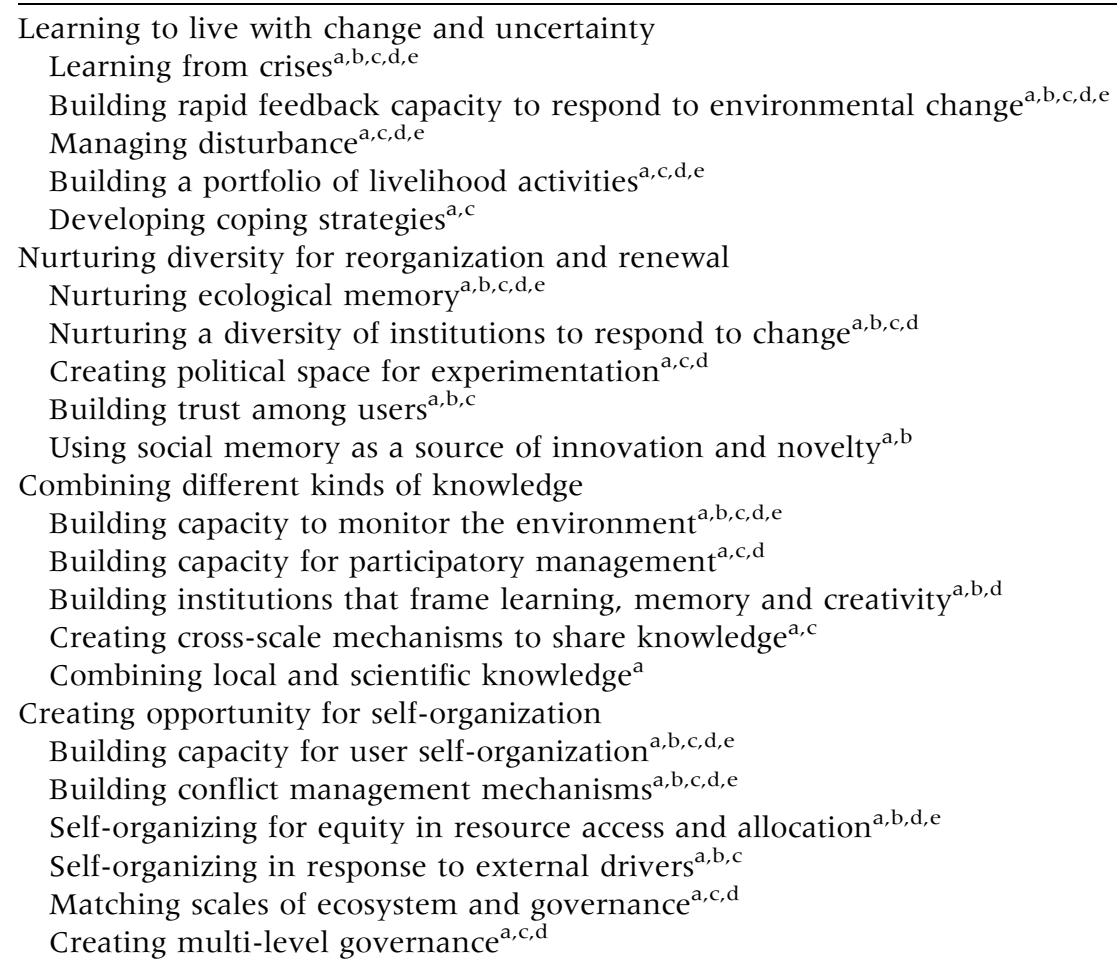

Categories based on Folke and others (2003). The numbers in parentheses refer to case studies that show a given item (cases and sources).

${ }^{a}$ Ibiraquera Lagoon, southern Brazil (Seixas and Berkes 2003)

${ }^{b}$ Cochin Estuary and lagoon, Kerala, India (Lobe and Berkes 2004)

'Patos Lagoon, southern Brazil (Kalikoski and others 2002; Reis and D'Incao 2000)

${ }^{d}$ Negombo Lagoon, Sri Lanka (Amarasighe and others 1997; Amarasighe and others 2002)

${ }^{e}$ Haylazli Lagoon, eastern Mediterranean coast of Turkey (Berkes 1986, 1992)

others 1995), but also for the provision of the bundle of components that makes adaptive renewal possible following a shock or disturbance event (Folke and others 2003). The cluster deals with reorganization and hence ecological and social memory, institutional diversity, trust, and innovation and novelty.

The most robust item in the cluster is nurturing ecological memory, for example, active management of the lagoon for entrance of shrimp larvae and fish fry, as in Ibiraquera (Seixas and Berkes 2003). In Negombo, fishers refrain from fishing the tidal inflow, the source of small shrimp into the lagoon. Stake net fishers fix their nets to harvest the shrimp migrating out to sea with the tidal outflow (Amarasinghe and others 1997; u.s. Amarasinghe personal communication), a pattern seen in the Cochin estuary as well (Lobe and Berkes 2004).

Nurturing institutional diversity is a key item for Patos Lagoon where the stakeholder body, called the "Forum", is composed of 21 groups and agencies operating at multiple levels from the local to the national (Kalikoski and others 2002), and the Negombo Lagoon in which there are historically well-established cross-scale linkages across three levels, from local to regional to national (Amarasinghe and others 1997). Creating political space for experimentation also stands out as an important item. In the Ibiraquera case, for example, results of the first rule modification in 1981 led fishers to demand other modifications in 1986 and in 1993-feedback learning and adaptive management made possible by the creation of political space for experimentation.

\section{Combining Different Kinds of Knowledge}

The third group of factors addresses the significance of local and traditional knowledge, experience and understanding of natural history and ecosystem dynamics (Berkes and others 2000), their inclusion 
in management institutions, and their potentially complementary relationship to conventional management (Folke and others 2003). Few ecosystems have been the subject of scientific studies, but many ecosystems are known to the people whose livelihoods depend on them. The five case studies produce different outcomes with respect to combining different kinds of knowledge, probably reflecting differences in the degree of community participation in management.

The Ibiriquera Lagoon, where participatory management experience has been strong, shows all five kinds of knowledge combination, whereas the other four do not. All cases, to various extents, involve building local fishers' capacity to monitor the environment, and three of the five cases entail building capacity for participatory management. Three cases show evidence of what Davidson-Hunt and Berkes (2003) have called institutions of knowledge, rules-in-use that frame or establish boundaries for learning, memory and innovation. Management practices of communities do not exist in a vacuum but are framed by the social context, as seen in the Cochin and Negombo cases, as well as in Ibiraquera. Such embedding of knowledge in local institutions is more typical of historically rooted local management systems (Folke and others 2003).

Examples of cross-scale sharing of knowledge are found in the two Brazilian cases, but not to any extent in the others. Combining local and scientific knowledge for lagoon resource management is well documented in the Ibiraquera case only (Seixas and Berkes 2003). The potential exists for such a combination in most, if not all, of the other cases.

\section{Creating Opportunity for Self-organization}

In this set, two kinds of factors stand out in terms of robustness: building capacity for user self-organization (social capital and collective action) and for conflict management. Both of these factors are fisher-driven; that is, self-organization and conflict management seem to emerge from communitybased social processes. The Cochin case is particularly striking because it shows that self-organization and conflict management can occur even in the absence of resource rights or government recognition of local institutions (Lobe and Berkes 2004). Equity in resource access and allocation was key to gear choice in Ibiraquera (Seixas and Berkes 2003) and in the choice of craft type in Haylazli (Berkes 1992). Rotation of netting sites in both Cochin and Negombo are related to equity.
Three other kinds of factors appear in three of the five cases. Self-organizing in response to external drivers is seen, for example, in the ways in which fishers in Ibiraquera and Cochin responded to the emergence of regional and international markets for shrimp. Attempts to match scales of ecosystem and governance are very evident in the Ibiraquera case in the way fishing groups have blended government regulations with locally evolved rules for the lagoon. Patos lagoon is probably the best example among the five with regard to the creation of multi-scale governance. This is a large lagoon with a complex set of user-groups. Co-management involves both horizontal and vertical linkages (Young 2002); however, such arrangements are both necessary and difficult to accomplish (Kalikoski and Satterfield 2004).

\section{Discussion and Conclusions}

We need to distinguish factors for building resilience, which we have identified in this paper for a selection of lagoon SES cases, and surrogates of resilience. There are a number of characteristics of surrogates of resilience: they must be forwardlooking (as opposed to current state); they must come in multiples or clusters to reinforce one another; and they must map onto theory, in this case, resilience theory (Carpenter and others 2005). Further, "a surrogate should be consistent and repeatable, in the sense that independent observers given the same information would assess the surrogate in the same way. Resilience surrogates will often be context-dependent, and the nature of this context-dependency should be spelled out. It should be possible to assess the surrogate for a range of SES, or in a SES over time. In general, the surrogate should be part of a set of complementary surrogates that address multiple aspects of resilience" (Carpenter and others 2005).

The search for local-level factors that build resilience in lagoon systems provides insights for the choice of surrogates through the identification of a number of factors that are robust across the five cases from various parts of the world (Table 1). However, the cases also indicate a number of other factors that may be key to building resilience but not universally used. These include creating political space for experimentation, combining local and scientific knowledge, matching scales of ecosystem and governance, and creating multi-scale governance. These factors are not robust across our lagoon cases but are clearly important for policy to build adaptive capacity (Folke and others 2002). 
Identifying factors for building resilience at the local level is an important first step that helps us understand what resilience might look like "on the ground". However, turning resilience factors of the sort identified in this paper into measurable indicators or surrogates is a step beyond the scope of this initial exploration. Some of these factors will be difficult to measure (for example, nurturing social or ecological memory). Many can be assessed qualitatively (for example, the existence of conflict management mechanisms, learning from crises; building trust) or semi-quantitatively (for example, multi-level governance, mechanisms to share knowledge). Some can be measured quantitatively, such as the mix of different kinds of fishing activities and the diversity of livelihood portfolios (Lobe and Berkes 2004) or the number of organized groups, as a measure of self-organizational capacity.

The choice of measurable indicators or surrogates often depends on the availability of data; such data tend to be organized at regional and national scales. This is generally the case for sustainability indicators (Meadows 1998) or natural resource performance indicators (Campbell and others 2001). Scale is important and multi-level analysis is essential (Cash and Moser 2000). The factors identified in Table 1 pertain to the local level because our objective is to understand resilience at the local level. Thus, Table 1 does not analyze for scale, but the use of surrogates and the way in which they are combined requires attention to scale (Campbell and others 2001).

Finally, we have clustered lagoon SES factors (Table 1) following the framework of Folke and colleagues (2003). No doubt there are other ways to cluster them. What is important, however, is to organize the factors in a way in which they reinforce one another. No single variable is likely to be robust across all systems. But a cluster of variables dealing, for example, with self-organization will be relevant to all systems. Hence, the use of clusters, as done in Table 1, will accommodate the differences between systems or cases, while capturing the multiple dimensions of a larger category such as uncertainty, diversity, knowledge and self-organization.

\section{ACKNOWLEDGEMENTS}

We thank members of the Resilience Alliance and the surrogates group for the stimulation; Upali Amarasinghe, Daniela Kalikoski and Kenton Lobe for lagoon management insights and suggestions for the paper; and Steve Carpenter and two anon- ymous referees for comments. The research was supported by the SSHRC and CRC for Berkes and the CNPq-Brazil for Seixas (Process: 200263/97-8).

\section{REFERENCES}

Allison EH, Ellis F. 2001. The livelihoods approach and management of small-scale fisheries. Mar Policy 25:377-88.

Amarasinghe US, Amarasinghe MD, Nissanka C. 2002. Investigation of the Negombo estuary (Sri Lanka) brush park fishery, with an emphasis on community-based management. Fish Manage Ecol 9:41-56.

Amarasinghe US, Chandrasekara WU, Kithsiri HMP. 1997. Traditional practices for resource sharing in an artisanal fishery of a Sri Lankan estuary. Asian Fish Sci 9:311-23.

Berkes F. 1986. Local-level management and the commons problem: a comparative study of Turkish coastal fisheries. Mar Policy 10:215-29.

Berkes F. 1992. Success and failure in marine coastal fisheries of Turkey. In: Bromley DW, Ed. Making the commons work. San Francisco: Institute for Contemporary Studies Press. p 161-82.

Berkes F, Colding J, Folke C. 2000. Rediscovery of traditional ecological knowledge as adaptive management. Ecol Appl 10:1251-62.

Berkes F, Folke C, Eds. 1998. Linking social and ecological systems: Management practices and social mechanisms for building resilience. Cambridge: Cambridge University Press.

Campbell B, Sayer JA, Frost P, Vermeulen S, Ruiz Pérez M, Cunningham A, Prabhu R. 2001. Assessing the performance of natural resource systems. Conserv Ecol 5(2):22. [online] URL: http://www.consecol.org/vol5/iss2/art22.

Carpenter SR, Westley F, Turner MG. 2005. Surrogates for resilience of social-ecological systems. Introduction to special feature of ecosystems. Ecosystems 8:xx-xx.

Cash DW, Moser SC. 2000. Linking global and local scales: designing dynamic assessment and management processes. Glob Environ Change 10:109-20.

Davidson-Hunt I, Berkes F. 2003. Learning as you journey: Anishinaabe perception of social-ecological environments and adaptive learning. Conserv Ecol 8(1):5. [online] URL: http:// www.consecol.org/vol8/iss1/art5.

Folke C, Carpenter S, Elmqvist T and others 2002. Resilience for sustainable development: Building adaptive capacity in a world of transformations. Paris: International Council for Scientific Unions (ICSU), Rainbow Series No. 3. [Online] URL: http://www.sou.gov.se/mvb/pdf/resiliens.pdf.

Folke C, Colding J, Berkes F. 2003. Synthesis: building resilience and adaptive capacity in social-ecological systems. In: Berkes F, Colding J, Folke C, Eds. Navigating social-ecological systems: Building resilience for complexity and change. Cambridge: Cambridge University Press. p 352-87.

Gunderson LH, Holling CS, Eds. 2001. Panarchy. Understanding transformations in human and natural systems. Washington DC: Island Press.

Kalikoski DC, Satterfield T. 2004. On crafting a fisheries comanagement arrangement in the estuary of Patos Lagoon (Brazil): opportunities and challenges faced through implementation. Mar Policy 28:503-522.

Kalikoski DC, Vasconcellos M, Lavkulich L. 2002. Fitting institutions and ecosystems: the case of artisanal fisheries management in the Patos Lagoon. Mar Policy 26:179-96. 
Lobe K, Berkes F. 2004. The padu system of community-based fisheries management: change and local institutional innovation in south India. Mar Policy 28:271-81.

Meadows DH. 1998. Indicators and information systems for sustainable development. Hartland (VT): Sustainability Institute.

Perrings CA, Mäler K-G, Folke C, Jansson BO, Holling CS, Eds. 1995. Biodiversity conservation. Dordrecht: Kluwer.

Reis EG, D'Incao F. 2000. The present status of artisanal fisheries of extreme Southern Brazil: an effort towards community-based management. Ocean Coast Manage 43:585-95.
Seixas CS, Berkes F. 2003. Dynamics of social-ecological changes in a lagoon fishery in Southern Brazil. In: Berkes F, Colding J, Folke C, Eds. Navigating social-ecological systems: building resilience for complexity and change. Cambridge: Cambridge University Press. p 271-98.

Walker B, Carpenter S, Anderies J, Abel N, Cumming G, Janssen M, Lebel L, Norberg J, Peterson G, Pritchard R. 2002. Resilience management in social-ecological systems: a working hypothesis for a participatory approach. Conserv Ecol 6(1):14. [Online] URL: www.consecol.org/vol6/issl/art 14.

Young O. 2002. The institutional dimensions of environmental change. Fit, interplay and scale. Cambridge (MA): MIT Press. 